\title{
Extraction of B-H Characteristics from Visualized Magnetic Domain Images by Bitter Method
}

\author{
Tadaharu FUJISAKU, Seiji HAYANO, Yoshifuru SAITO and Kiyoshi HORII
}

\begin{abstract}
The Bitter method is most easily observing way of the magnetic domains even though it is limited to the surface. To observe the magnetic domains by Bitter method, magnetic liquid is put on the target magnetic material after electrical field polishing process. Applying magnetic field to this magnetic material covered by magnetic fluid makes it possible to observe the magnetic domain dynamics by a microscope.

Principal purpose of this paper is to develop a magnetization measurement device for quality control of the magnetic materials by visualizing the magnetic domains by Bitter method. As a first step of our project, we reveal that local magnetization characteristics could be evaluated by means of the Bitter method.
\end{abstract}

Keywords: Magnetic domain dynamics, Silicon steel simulation

\section{1. 緒 論}

磁性鋼板は電気・電子機器を構成する主要な材料であ る.一般に, 磁性材料は磁区と呼ばれる微小磁石の集合 で構成され，外部磁界に応じて材料中の磁気エネルギー が最小となるように磁区が変化する. すなわち，磁性材 料の磁化過程は外部磁界に対する磁区挙動である. 所望 の磁化特性を持つ材料開発・評価に, 磁区挙動の可視化 は磁化過程を掌握するために重要な役割を担う。磁区举 動の可視化は, 磁性コロイド溶液を用いたビッター法,

電子顕微鏡に拠る方法, 磁気光学効果を利用した方法等 で行われる1)。ビッター法は手軽な方法であるが, 磁区 間の磁壁しか観察できない.また, 磁気光学的方法は磁 性体表面の磁区挙動可視化に限定される. 電子顕微鏡に 拠る方法は磁性体内部の磁区挙動を観察可能とするが, 高価な機器を必要とする.

従来, 我々は磁区の電子顕微鏡画像から磁性体の磁化 特性を抽出する全く新しい方法を提案した，現在，我々 は安価な設備で磁性体の磁区を可視化可能とするビッタ 一法を用いて磁性体の磁化特性を抽出する方法を開発し ている. 第一段階として, 磁性体の磁区画像と磁化特性 の関係を把握するため, 球状永久磁石を使ったハードウ

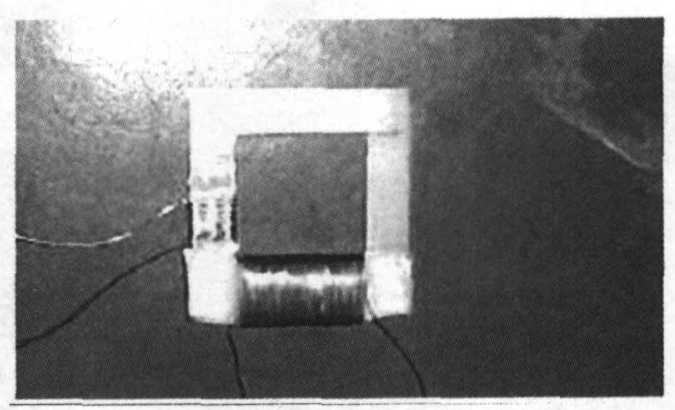

Fig. 1 Tested Yoke and Exciting Coil エアシミュレーションを行い, 方法の妥当性を検証した 2). 本論文では実際にビッター法で磁区動画像の可視化 を行い, その結果から局所的な磁化特性が把握出来るか を検証する.

本論文の構成は 4 章からなる. 1 章は緒論であり，本 研究の社会的な背景と目的について述べた. 2 章は磁性 体の磁区可視化法について述べる.すなわち, ビッター 法を用いて磁性鋼板の動的磁壁移動を可視化する. 3 章 では可視化した画像から平均值差分法を用いて静止部分 を削減し，動的部分より磁化曲線を描く．4 章はまとめ である。 


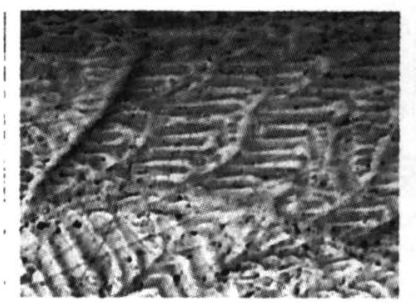

$0.00 \mathrm{~s}$

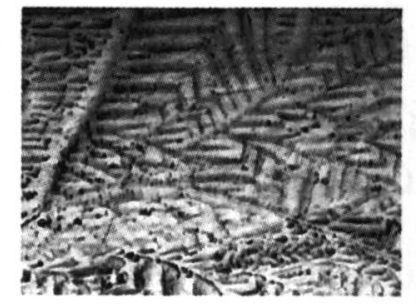

$0.2 \mathrm{~s}$

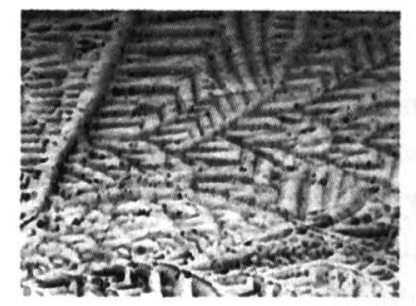

$0.4 \mathrm{~s}$

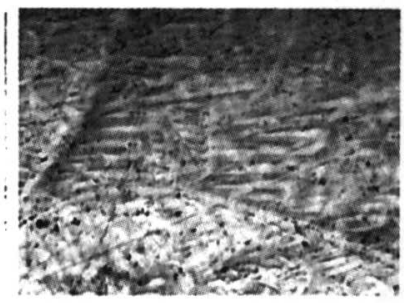

$0.6 \mathrm{~s}$

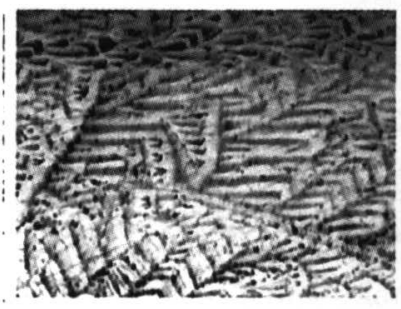

$0.8 \mathrm{~s}$

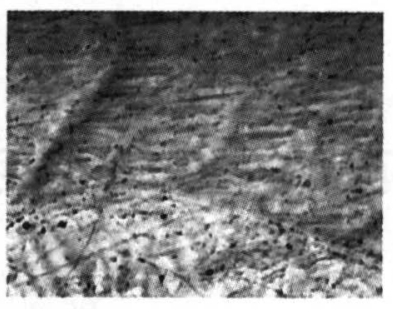

$0.07 \mathrm{~s}$

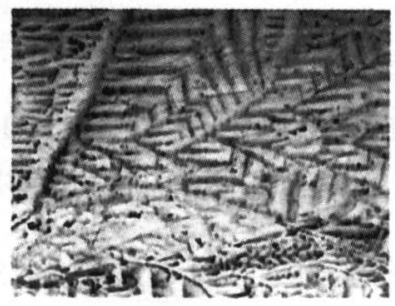

$0.26 \mathrm{~s}$

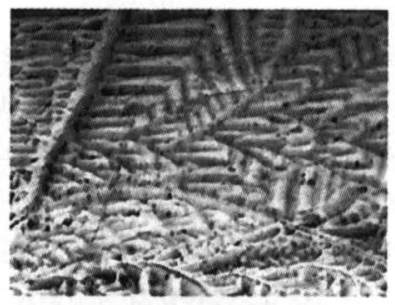

$0.46 \mathrm{~s}$

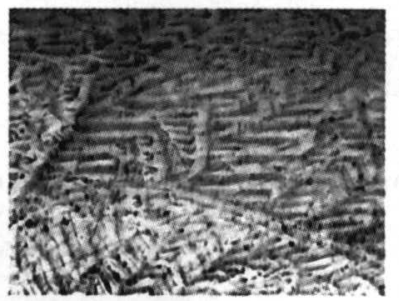

$0.66 \mathrm{~s}$

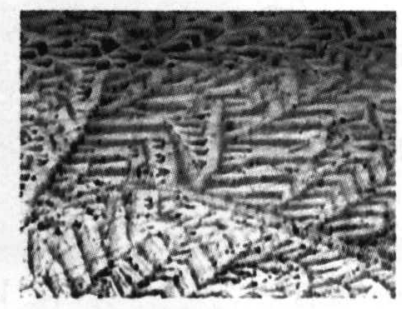

$0.86 \mathrm{~s}$

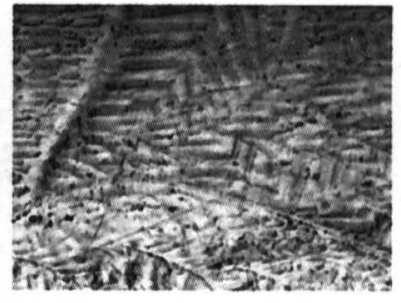

$0.13 \mathrm{~s}$

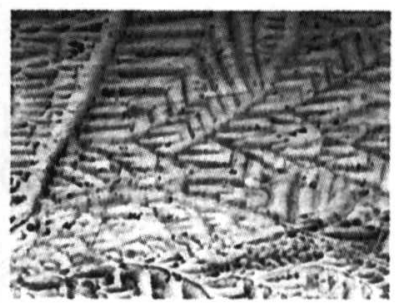

$0.33 \mathrm{~s}$

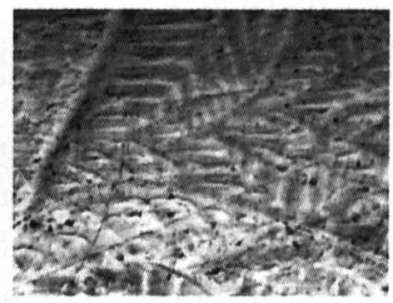

$0.53 \mathrm{~s}$

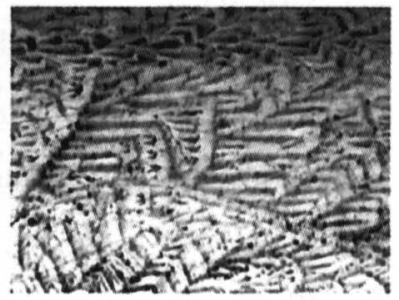

$0.73 \mathrm{~s}$

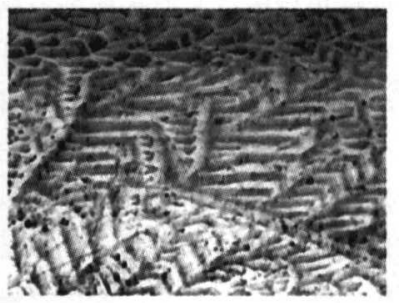

$0.92 \mathrm{~s}$

Fig. 2 Visualized Magnetic Domain Images by Bitter Method

\section{2. 動磁区画像}

\section{1 ビッター法による磁壁移動の可視化}

磁性材料の表面の磁区を観察するには，反射型の金属 光学顕微鏡を用いる. 試料台に試料を載せて, 研磨した 試料面にスポイトで磁性コロイド溶液をたらし，カパー ガラスを載せて観察する．強磁性微粒子（ $\gamma$ 酸化鉄）の コロイド液を強磁性体表面につけると，コロイド夜内に 分散していた酸化鉄の微粒子が，磁壁付近の急峻な磁化 変化による表面への漏れ磁束の傾斜に引き付けられて集 まり，表面近くの磁壁の観測ができる．この引き付けら
れた微粒子を光学顕微鏡で観察する ${ }^{3)}$.この原理はマグ ネットビューワー商品などに応用されており, 比較的面 倒な実験準備を必要とせずに, 実行可能である.

今回は珪素鋼板を電解研磨法によって研磨し, 磁区観 測用コロイド溶液をたらし, 顕微鏡により観測を行った. 顕微鏡の倍率は 450 倍である.

\section{2 磁壁移動の可視化}

Fig. 1 は磁壁移動の可視化に使用した実験装置であ る. 検出コイルと励磁コイルを設けてある. 励磁コイル へ周波数 $1 \mathrm{~Hz}$ の正弦波交流電流を通電し, 磁界をサンプ 
ル珪素鋼板に印加する．珪素鋼板に磁界を印加すると， 印加磁界に対して磁気エネルギーが最小になるために磁 壁が移動し，その結果として，磁壁に吸着された酸化鉄 の微粒子が移動する. 従って, 酸化鉄の微粒子, すなわ ち, 磁性流体の動きを撮影することで磁壁の挙動が可視 化される. 本実験では画像は NTSC 方式のモノクロ動画 像である. Fig. 2 は可視化された磁区動画像の各フレー ムを示す.

3. 磁区動画像と磁化特性

3.1 背景画像之磁区動画像

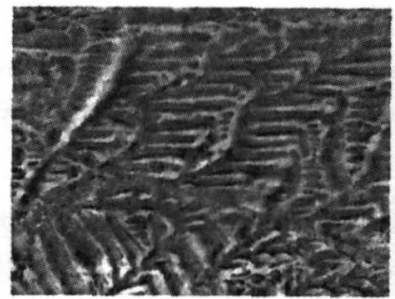

$0.00 \mathrm{~s}$

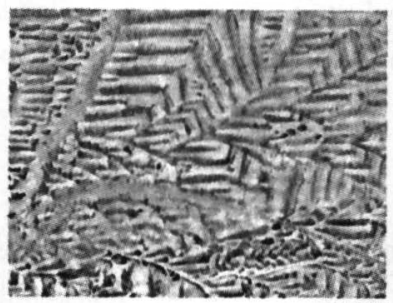

$0.2 \mathrm{~s}$

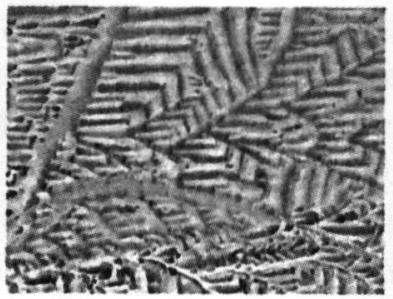

$0.4 \mathrm{~s}$

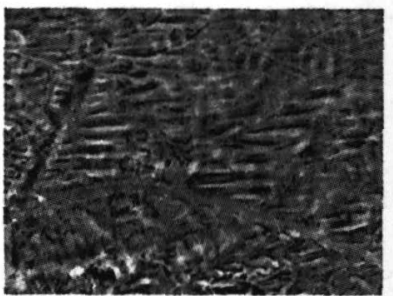

$0.6 \mathrm{~s}$

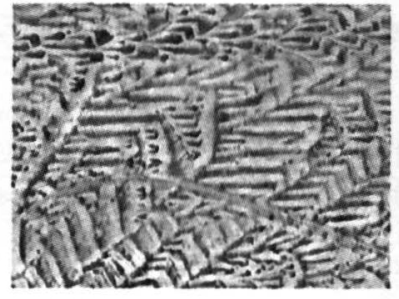

$0.8 \mathrm{~s}$

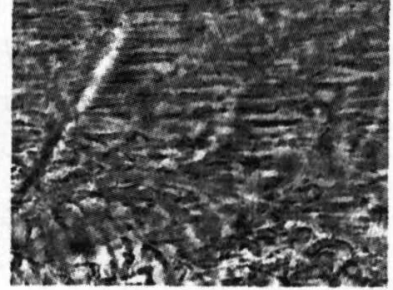

$0.07 \mathrm{~s}$

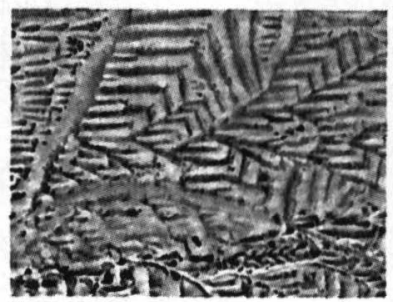

$0.26 \mathrm{~s}$

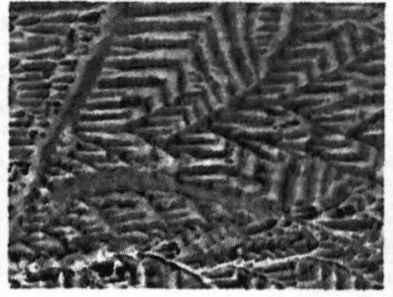

$0.46 \mathrm{~s}$

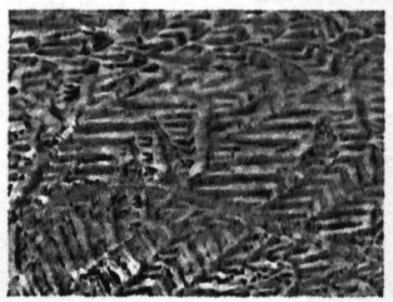

$0.66 \mathrm{~s}$

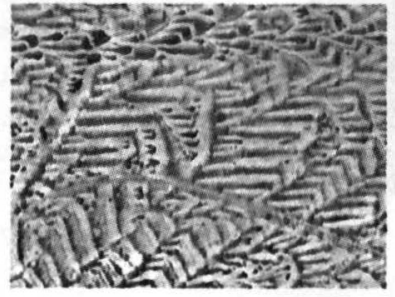

$0.86 \mathrm{~s}$

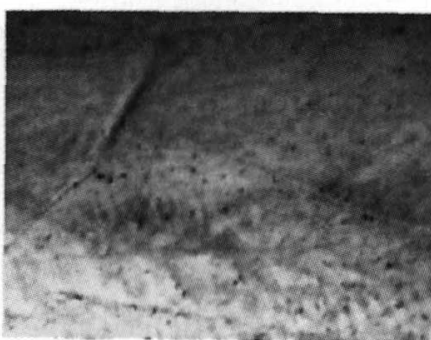

Fig. 3 Static Magnetic Domain Image derived as an average of entire frame images in Fig. 2

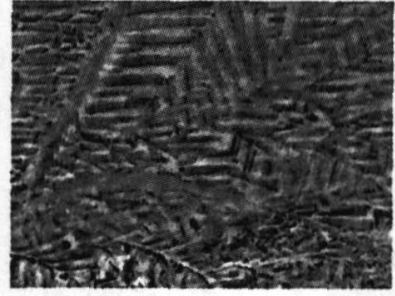

$0.13 \mathrm{~s}$

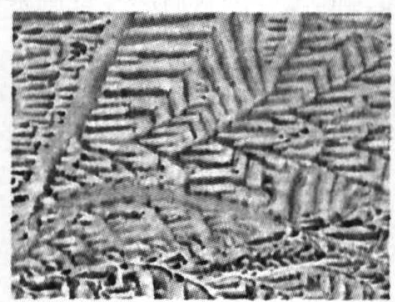

$0.33 \mathrm{~s}$

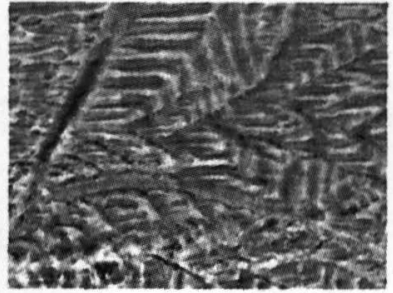

$0.53 \mathrm{~s}$

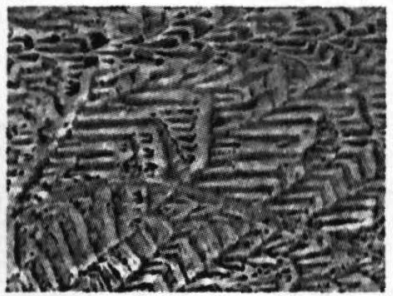

$0.73 \mathrm{~s}$

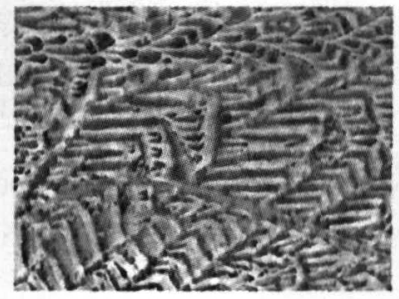

$0.92 \mathrm{~s}$

Fig. 4 Dynamic Magnetic Domain Images not Including Static Background Image in Fig. 3 
前節では，磁壁移動に対応する磁性流体の動画像を Fig. 2 に示した. Fig. 2 のフレーム画像では, 磁性流体の 不動部分と珪素鋼板そのものの物理的な傷などが背景画 像として含まれている.

Fig. 2 のフレーム画像から背景画像を削除して動画像 部分のみを抽出することを考える. 従来, 対称境界条件 を設定した 2 階偏微分方程式から導かれるモーダルウェ ーブレット変換のマザーウェーブレット部分が背景画像 であることが知られている4)。このマザーウェーブレッ 卜部分は全フレーム画像で同一画素位置の画素値の平均 值に対応するから，全フレームから背景画像が抽出可能 であり, Fig. 3 が結果として得られた背景画像である.

Fig. 4 はFig. 2 の各フレーム画像から背景を削除し て得られた動画像の各フレーム画像である.

\section{2 磁化特性}

Fig. 4 の各フレーム画像の濃淡で表されている画素値 とサーチコイルを使って得られる平均的磁束密度を対応 させて, 画像の画素值から各画素位置の磁化特性を算出 する. 平均的磁束密度は式(1)のファラデーの法則に基つ く誘起電圧 $\mathrm{v}(\mathrm{t})$ を積分して得られた磁束鎖交数から算出 した ${ }^{5)}$. Fig. 5 に平均的磁化曲線を示す.

$$
v(t)=-N \frac{d \varphi(t)}{d t}
$$

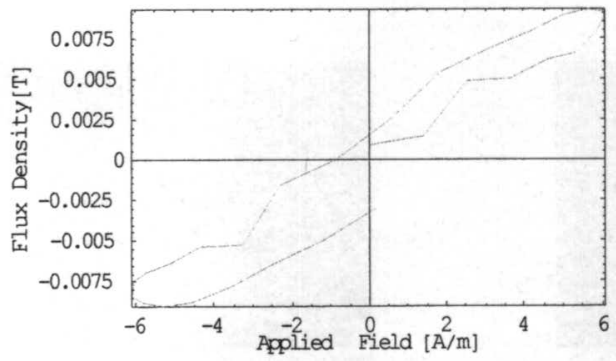

Fig. 5 Averaged Magnetization Characteristic Curve

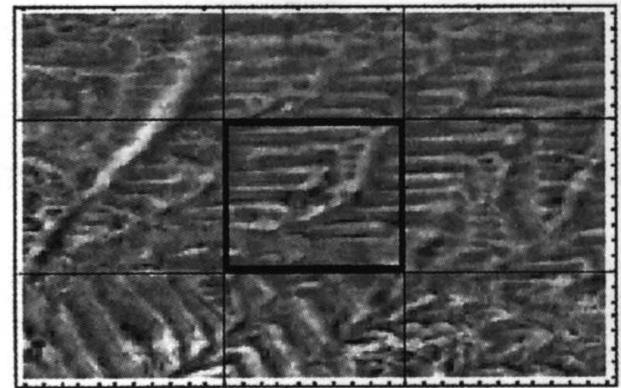

Fig. 6 Sample Area for Local Magnetization Characteristic Extraction

Fig. 6 は局所的磁化曲線を描くためのある領域を示し
ている. Fig. 6 の, 画素値の座標 $\left(\begin{array}{lllll}1 & 1 & 0\end{array}, 700\right)$ を始点 として幅 100 , 高さ 100 の $100 \times 100$ の正方形 の範囲（黒枠内）の磁化特性を求める.

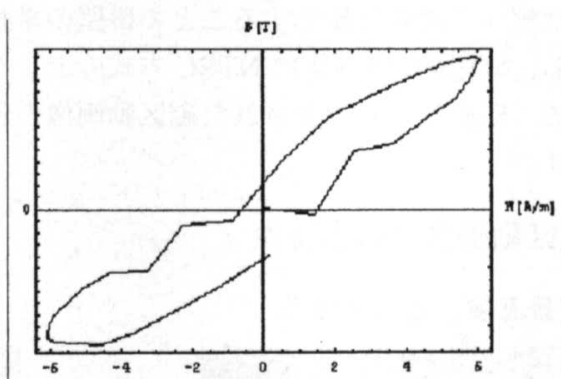

Fig. 7 Local Magnetization Characteristic Curve in the Area enclosed by Black Square Box

Fig. 5 に各磁界と平均的磁束密度が与えられている から、Fig. 4 の各フレーム画像の平均画素值と磁束密度 值を対応させることで，相対的に正方形の範囲における 局所的磁化特性を求めることができる. Fig. 7 は得られ た局所的磁化特性である。

\section{4.まとめ}

本論文では, 磁区挙動, 磁壁移動が磁性体の磁化過程 に結びついていることに着眼し, 磁壁移動を可視化した 画像から，局所的磁化特性を評価する方法を提案した.

実際の磁性鋼板の磁壁移動をビッター法により可視化 し, 可視化された磁壁移動の画像の濃淡值から局所的磁 化特性を評価する方法を提案した，従来，筆者らが提案 した球状永久磁石を用いたハードウェアシミュレーショ ン結果と同じ傾向の結果を本論文で提案した手法で得た. これは,これまで経験豊かな技術者の目視により行われ てきた磁性材料の磁化特性評価が計算機を用いて自動化 され高精度・高速に行える可能性を示唆している。

\section{参 考文 献}

1) Alex Hubert, Rudolf Schaefer: "Magnetic Domains" (Springer. 1998).

2）大寉雄亮, 遠藤久, 早野誠治, 齊藤兆古, 堀井清之: 球状永久 磁石を用いて模擬した磁性鋼板の動的磁区挙動の可視化, 可視化情報, Vol. 23, No. 1 (2003) pp. 263-266.

3）川西健次, 近角聰信, 櫻井良文: 磁気工学ハンドブック, 朝 倉書店 (1998)

4) H Endo, I. Marinova, S. Hayano, Y. Saito, and K.Horii"” Modal-Wavelets and Their Applications," (JSAEM Studies in Applied Electromagnetics and Mechanics 14 pp.279-284 IOS Press, The Netherland,2003).

5) 山田直平 : 電気磁気学, 電気学会, オーム社. 